\title{
Applying the ADDIE-Analysis, Design, Development, Implementation and Evaluation-Instructional Design Model to Continuing Professional Development for Primary Care Physicians in Saudi Arabia
}

\author{
Rabaa K. Almomen ${ }^{*}$, David Kaufman ${ }^{2}$, Haifa Alotaibi1 ${ }^{1}$, Noura Abdullah Al-Rowais ${ }^{1}$, \\ Mohamad Albeik ${ }^{1}$, Saad M. Albattal ${ }^{1}$ \\ ${ }^{1}$ Family \& Community Medicine Department, Prince Sultan Medical Military City, Riyadh, KSA \\ ${ }^{2}$ Faculty of Education, Simon Fraser University, Burnaby, BC, Canada \\ Email: "rabaa_almomen@yahoo.com
}

Received 18 July 2016; accepted 12 August 2016; published 15 August 2016

Copyright (C) 2016 by authors and Scientific Research Publishing Inc.

This work is licensed under the Creative Commons Attribution International License (CC BY). http://creativecommons.org/licenses/by/4.0/

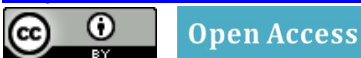

\begin{abstract}
Background: As professionals, family physicians are obliged to remain current on advances and trends in medicine and health care delivery. This is usually achieved through engagement in continuing professional development. Instructional design is a systematic method of development of education and training programs for improved learner performance. ADDIE is an instructional systems design model for building effective education and training in five phases: analysis, design, development, implementation and evaluation. Purpose: The purpose of this study was to introduce a professional development program for primary care physicians using the ADDIE instructional design model. Methods: Program requirements were defined using a needs assessment questionnaire and consultation observations. Interactive sessions were designed and developed based on the analysis results. The sessions were evaluated with interim and final feedback forms, a final problem-based questionnaire, a self-assessment questionnaire, and focus groups. Results: Scores on the final knowledge assessment were lower than expected. However, at least $50 \%$ of participants self-reported their learning improvement as "great" for 16 out of 23 topics. Focus group feedback was generally positive but also identified areas for improvement. Conclusion: Applying a structured instructional design model for creating professional development program for physicians is a fruitful, relevant experience in primary healthcare. 1) Continuing professional development (CPD) is an essential method to help physicians maintain and further develop know-
\end{abstract}

*Corresponding author.

How to cite this paper: Almomen, R.K., Kaufman, D., Alotaibi, H., Al-Rowais, N.A., Albeik, M. and Albattal, S.M. (2016) Applying the ADDIE-Analysis, Design, Development, Implementation and Evaluation-Instructional Design Model to Continuing Professional Development for Primary Care Physicians in Saudi Arabia. International Journal of Clinical Medicine, 7, 538-546. http://dx.doi.org/10.4236/ijcm.2016.78059 
ledge and expertise; 2) The ADDIE (analysis, design, development, implementation, evaluation) model provides an established and useful structure for creating effective CPD programs; 3) The ADDIE process ensures that physicians' appropriate learning needs are met effectively; 4) The evaluation phase of the ADDIE process provides feedback that can lead to improvement in the CPD program's future iterations.

\title{
Keywords
}

\author{
ADDIE, Health Care Delivery
}

\section{Introduction}

Physicians and other team members in primary health care are expected to work with their colleagues independently to provide required services to their patients and their families. Graduation from accredited medical colleges and postgraduate medical residency programs provide the knowledge and skills necessary to enter the profession and practice with patients [1]. As professionals, family physicians are obliged to remain current on advances and trends in medicine and health care delivery [2]. This is usually achieved through engagement in a variety of activities that constitute continuing professional development (CPD) [3]. Professional development, also called staff development, is the process of improving staff capabilities through access to education and training opportunities in the workplace, often provided by an outside organization or by watching others performance on the job [4]. Professional development helps build and maintain staff members' morale and is thought to attract higher quality staff to an organization [5].

In the medical context, continuing medical education (CME) refers to the same concept, i.e., providing education to maintain and improve professional competency among health care workers [4]. Strategies used to develop CME have been evaluated and often criticized as ineffective for achieving its intended goals [6] [7]. Performance evaluation of health employees, on the other hand, is a mandate of all organizations including hospitals, as well as primary care and community health services for monitoring staff performance, motivation, and professional development. Participation in CPD and CME could be used in performance evaluation, in addition to other work performance indicators such as staff attendance, clinical skills and work-related attitudes. However, most staff evaluation is based on pre-employment agreements, expectations, and/or job definitions [1].

Instructional design (ID) is a systematic method of development of education and training programs for improved learner performance [8]. Over the last decades, practitioners have developed a number of models for instructional design (ID) [9]. An ID model is a set of main elements and tasks within a representation of real environment, developed to help educators and instructional designers incorporate fundamental elements of ID principles into a manageable process [9] [10]. The ID model is built upon some basic concepts about learning and instruction: firstly, learning takes place within an individual, involving cognitive and motor functions that lead to behavior. Secondly, instruction is the formal act of facilitating learning. One must therefore design the learning experience/instruction in such a manner that it will optimize learning. The development of appropriate ID approaches is one way to optimize learning through the design of the instructional process [8]. Instructional design is the key tool to establish systematic CPD that can ensure professional improvement, credibility and transparency to the community by analyzing, designing, developing, implementing, and evaluating the CPD education program [11].

Such education programs must provide high quality training built on strategic planning using an effective ID process. The CPD challenge is how to implement an effective program and performance evaluation that is valid, reliable, and practical for primary care physicians based on decisions about what should be expected from the physician, who is already certified, works in solo clinics most of the time, and is expected to manage a variety of patient problems.

Many professional instructional designers have applied the generic ADDIE framework [10] as a standard model for technology-based education. ADDIE is an instructional systems design model that presents a series of iterative steps for building effective education and training in five phases: analysis, design, development, implementation and evaluation. 


\section{Purpose}

The purpose of this study was to introduce a professional development program for primary care physicians using the ADDIE (Analysis, Design, Development, Implementation, Evaluation) instructional design model to improve primary care physicians' clinical performance.

\section{Methods}

The study involved 37 primary care physicians working in the Family and Community Medicine Department of Prince Sultan Medical Military City in Riyadh, Saudi Arabia. This department is one of the largest departments of this medical city and comprises several community centers with different numbers of physicians and target populations. Physicians are ranked in the department according to their background, medical affiliations, and experience in the categories of consultant, senior registrar, registrar, and senior house officer. The last two categories are the ones that constitute the focus of this study.

The analysis phase of the ADDIE model started by dividing 37 doctors into four smaller, mostly equal groups. The main program objective was to improve the approach to patients' clinical management WHAT KIND?, enhance doctor-patient communication skills and support doctors on their decision for investigations and prescribing rationally rationalizing resources?. Before beginning the program, a survey was sent to all participants to inquire about their perceived performance gaps, their main problems during work in the clinics, and their preferred style of learning (Appendix 1). Rounds were scheduled to observe doctors' consultation skills based on a patient consultation observation model (Appendix 2).

For the design, development, and implementation phases, six sessions were conducted over six months with each group on different medical topics. MORE DETAIL ON THESE PHASES? SOME DESCRIPTION?

Before beginning the program, a survey was sent to inquire about doctors' performance gaps, their main problems during working in the clinics, and the style of learning they would prefer. Rounds were scheduled to observe doctors' consultation skills based on a consultation observation model with patients (Appendix 1). The design, development and implementation phases are summarized as follows. Six sessions were conducted over six months with each group on different medical topics .Facilitators of the sessions were chosen from the departments in which consultants and senior trainers had more experience and/or qualifications in dealing with common family medicine problems. The sessions were designed to be interactive and case-based discussions were prepared on the topics listed (Table 1 ).

Cases were discussed in an interactive manner among facilitators and candidates and materials were provided if a topic required reading or preparation ahead of time. Some topics required presentation of slides, others

\section{Table 1. Topics included in the case-based discussions.}

- Clinical approach to cardiovascular risk assessment using the ATPIII guidelines and Framingham point scores

- Bronchial asthma assessment in children and adults (severity and control)

- Use of inhalers and expiratory peak flow meters

- Management of dysfunctional uterine bleeding

- Management of a woman presenting with amenorrhea

- Management of polycystic ovary diseases in the clinics

- Management of a child presenting with fever with or without skin rash

- Management of a child presenting with abdominal pain

- Management of a coughing child

- Dealing with parents presenting with a child who is not eating well/ failing to thrive

- Children with otitis media and tonsillitis

- Describing a skin lesion

- Acne vulgaris modalities of management in family medicine

- Management of hair loss in men/women

- Commonly presenting skin fungal infections in primary care

- Referral letter writing

- Rationalizing resources

- Doctor-patient communication 
required dummies for examination, and case scenarios with role plays were used to highlight communication issues (Table 2).

Facilitators of the sessions were chosen from the departments in which consultants and senior trainers had more experience and/or qualifications in dealing with common family medicine problems. The sessions were designed to be interactive, and case-based discussions were prepared on the topics listed in Table 1. Cases were discussed in an interactive manner among facilitators and candidates, and materials were provided if a topic required reading or preparation ahead of time. Some topics required presentation of slides, others required dummies for examination, and case scenarios with role-plays (e.g., see Table 2) were used to highlight communication issues.

Evaluation of the program was done using multiple instruments. An evaluation form was used to evaluate individual sessions and facilitators. At the end of the six-month program, participants completed a final problem-based multiple-choice assessment, a form-based evaluation of the program, and a self-assessment questionnaire. Focus group discussions were conducted for both participants and trainers to explore their feelings and perceptions about the program activities.

\section{Results}

Twenty-six out of the 37 physicians attended the sessions over the six-month period and completed both the final knowledge test and the self-assessment test. The remaining 11 participants were removed from the sessions to meet service needs or did not complete the full six months' attendance due to leaves.

Figure 1 summarizes scores on the final knowledge assessment. The average mark was 35 correct answers out of 50 questions, ranging from 24 to 39; the majority of participants scored between 34 and 40 .

Table 3 summarizes the results of the self-assessment questionnaire. Six participants' self-assessments were removed from the analysis because they attended less than three sessions. For 16 out of the 23 topics discussed, at least $50 \%$ of participants rated their improvement as a result of attending the group sessions and discussions as "great". Dermatology topics, however, showed less improvement.

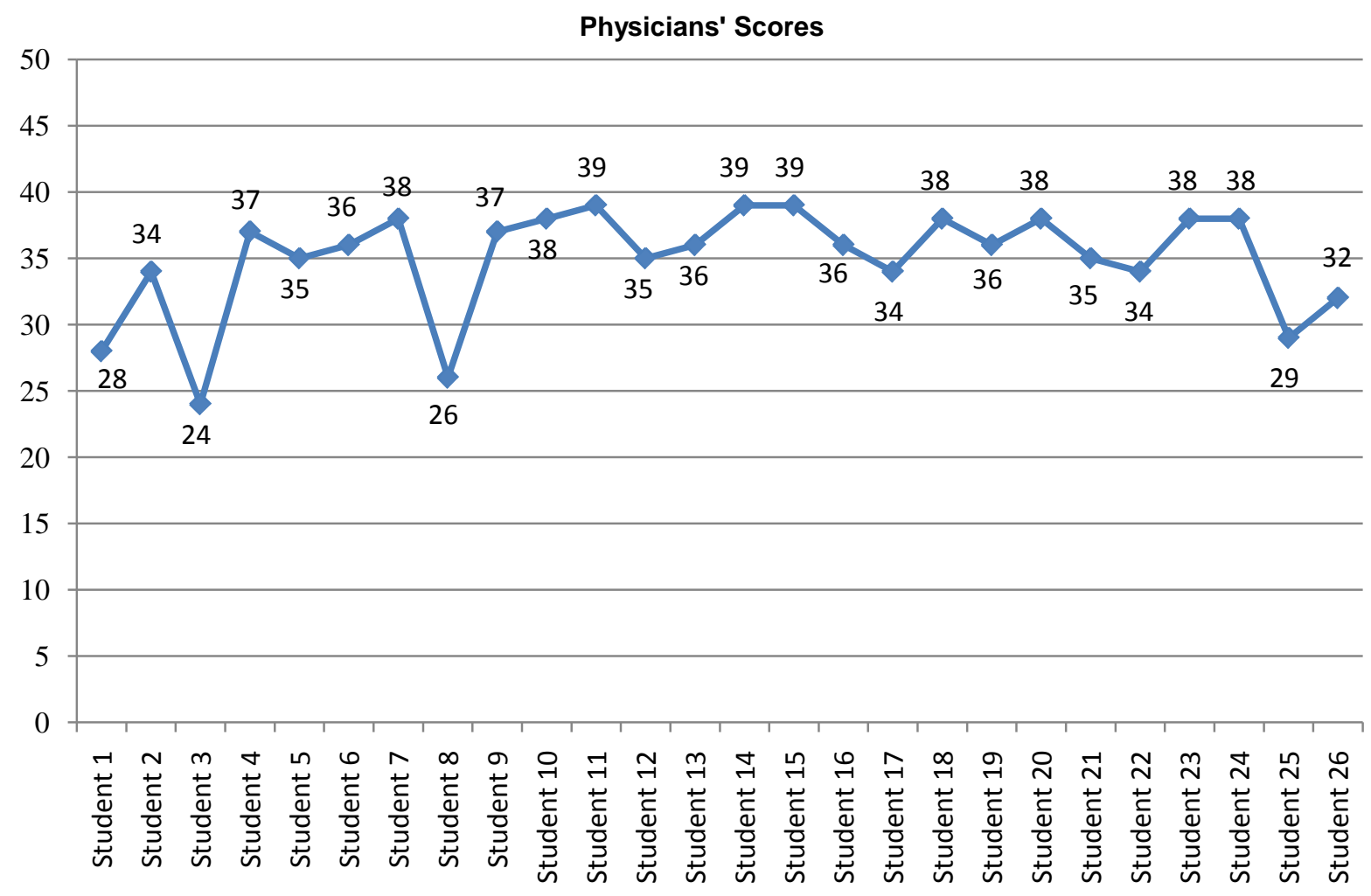

Figure 1. Physicians' scores on the final test of 50 items about clinical topics attended $(n=26)$. 
Table 2. Sample case used in the CPD sessions.

\begin{tabular}{|c|c|c|c|}
\hline Topic & Case & Question & Competencies Required \\
\hline $\begin{array}{l}\text { 18-month-old } \\
\text { child with adenoids }\end{array}$ & $\begin{array}{l}\text { Mother and father presenting } \\
\text { with a child breathing } \\
\text { through the mouth for the } \\
\text { last three months with } \\
\text { disturbed sleep and } \\
\text { continuous runny nose }\end{array}$ & $\begin{array}{l}\text { What is your } \\
\text { management } \\
\text { approach? }\end{array}$ & $\begin{array}{l}\text { - Definition of the problem } \\
\text { - Assessment of the child's general wellbeing based on } \\
\text { - Aistory and examination } \\
\text { - } \text { Assessment of child's risk factors } \\
\text { basideration of different management approaches } \\
\text { - Sharing decision options with parents } \\
\text { - Consideration of parents' worries and anxieties }\end{array}$ \\
\hline
\end{tabular}

Table 3. Physicians’ self-assessments of their level of improvement $(\mathrm{N}=20)$ as a result of attending the six-month course*.

\begin{tabular}{|c|c|c|c|c|}
\hline \multirow[b]{2}{*}{ Medical topic } & \multicolumn{4}{|c|}{ Improvement } \\
\hline & $\begin{array}{l}\text { None } \\
N(\%)\end{array}$ & $\begin{array}{l}\text { Slight } \\
N(\%)\end{array}$ & $\begin{array}{c}\text { Moderate } \\
N(\%)\end{array}$ & $\begin{array}{l}\text { Great } \\
N(\%)\end{array}$ \\
\hline Cardiovascular risk clinical assessment in primary care & $0(0)$ & $5(25)$ & $5(25)$ & $10(50)$ \\
\hline Use of ATP/Framingham risk score & $1(5)$ & $2(10)$ & $6(30)$ & $11(55)$ \\
\hline Communicating risk to patients & $0(0)$ & $2(10)$ & $8(40)$ & $10(50)$ \\
\hline Rational investigations, e.g., lipids and diabetes screening & $1(5)$ & $4(20)$ & $5(25)$ & $10(50)$ \\
\hline Assessment of severity of an asthmatic patient condition & $2(10)$ & $3(15)$ & $3(15)$ & $12(60)$ \\
\hline Assessment of control of an asthmatic patient condition & $3(15)$ & $2(10)$ & $5(25)$ & $10(50)$ \\
\hline Proper use of inhalers & $3(15)$ & $2(10)$ & $5(25)$ & $10(50)$ \\
\hline Use of peak flow meter & $3(15)$ & $2(10)$ & $5(25)$ & $10(50)$ \\
\hline Management of women presenting with irregular bleeding & $0(0)$ & $5(25)$ & $6(30)$ & $9(45)$ \\
\hline Management of women presenting with missed periods & $2(10)$ & $2(10)$ & $4(20)$ & $12(60)$ \\
\hline Polycystic ovary diseases-common clinical presentations & $3(15)$ & $4(20)$ & $3(15)$ & $10(50)$ \\
\hline Management of feverish child presenting with/ without rash & $2(10)$ & $4(20)$ & $2(10)$ & $12(60)$ \\
\hline Management of a child presenting with abdominal pain & $1(5)$ & $4(20)$ & $4(20)$ & $11(55)$ \\
\hline Parents presenting with child who is not eating well & $1(5)$ & $4(20)$ & $4(20)$ & $11(55)$ \\
\hline Earaches in children & $1(5)$ & $5(25)$ & $3(15)$ & $11(55)$ \\
\hline Tonsillitis in children & $3(15)$ & $2(10)$ & $5(25)$ & $10(50)$ \\
\hline Describing a skin lesion & $2(10)$ & $6(30)$ & $4(20)$ & $8(40)$ \\
\hline Writing a letter to a dermatologist & $2(10)$ & $6(30)$ & $5(25)$ & $7(35)$ \\
\hline Management of acne vulgaris & $2(10)$ & $8(40)$ & $2(10)$ & $8(40)$ \\
\hline Management of a woman presenting with hair loss & $1(5)$ & $6(30)$ & $7(35)$ & $6(30)$ \\
\hline Baldness in men—different management modalities & $2(10)$ & $6(30)$ & $6(30)$ & $6(30)$ \\
\hline Rational investigation, e.g., zinc/vitamin D/vitamins & $1(5)$ & $5(25)$ & $5(25)$ & $9(45)$ \\
\hline Communicating and explaining to patients & $1(5)$ & $6(30)$ & $3(15)$ & $10(50)$ \\
\hline
\end{tabular}

*Six participants did not complete this self-assessment form. 
In addition to the above-mentioned assessments, a focus group discussion was conducted to explore physicians' feelings and perceptions about the effect of being enrolled in these kinds of activities as a form of professional development. Participants made positive comments regarding reviewing the topics from the clinical point of view and reflecting on the problems that they faced in their daily work. One of the participants voiced her opinion as "We have the knowledge background from basic education, but sometimes we need to review and share different views". Another said that "It's is a brilliant idea to be pulled out of work once a month for the purpose of continuing education and professional development".

However, participants were concerned about the issue of the final appraisal being part of their annual employee review, as a result of participating in this program. Participants often questioned the need for the final test and queried the weight of the final assessment on contract renewal. In addition, the trainers who facilitated the sessions were concerned about the variability between their usual teacher-directed teaching styles and their learner-centered group facilitation experience.

\section{Discussion}

This study highlighted our valuable experience with the process of physicians' continuing professional development in primary care. Application of the ADDIE model through a pre-designed, structured small-group review and discussions of relevant clinical topics led to better identification of physicians' professional performance. The final objective assessment of clinical knowledge was identified as lower than expected for a practicing physician; the average score was 35/50 (70\%). This finding could be attributed to problems in the physicians' clinical knowledge application due to workload issues or maybe a result of employee selection. Analyzing this further could be fruitful for the organization and patient care.

Participants' evaluations of individual sessions identified issues such as low satisfaction scores for the dermatology sessions, where findings did not indicate significant improvement. Exploring the study participants' and trainers' views regarding the activity highlighted issues needing improvement such as the quality of training and employee appraisal.

Evaluating the effectiveness of different models of CPD is not new to the literature. As mentioned earlier, CPD is required for all physicians for reasons including improving performance and quality of care [12]. The workloads and structure in primary care mandate a different design and development process. The formats of conducting national and international events such as large audience conferences and big workshops might not always fulfill the purpose. Instructional design is the key tool to establishing a systematic CPD process that can ensure professional improvement, credibility and transparency to the community by analyzing, designing, developing, implementing, and evaluating the CPD education program [11].

\section{Conclusion}

Applying a structured instructional design model for creating professional development program for physicians is a fruitful, relevant experience in primary healthcare. We recommend that this study be repeated on a wider national and international scale.

\section{Declaration of Interest}

The authors report no declarations of interest.

\section{References}

[1] Choudary, G.B. and Purnik, S. (2014) A Study on Employee Performance Appraisal in Health Care. Asian Journal of Management Sciences, 2, 59-64.

[2] Toon, P. (1997) Educating Doctors to Improve Patient Care. BMJ, 315, 326. http://dx.doi.org/10.1136/bmj.315.7104.326

[3] Paterson, K. (2002) The Professional Development of Principals: Innovations and Opportunities. Educational Administration Quarterly, 38, 213-232. http://dx.doi.org/10.1177/0013161X02382006

[4] Towle, A. (1998) Changes in Health Care and Continuing Medical Education for the 21st Century. BMJ, 316, $301-304$. http://dx.doi.org/10.1136/bmj.316.7127.301

[5] Brigley, S., Young, Y., Littlejohn, P. and McEwen, J. (1998) Continuing Education for Medical Professionals: A Ref- 
lective Model. Postgraduate Medical Journal, 73, 23-26.

[6] Booth, B. (1997) Does Continuing Medical Education Make a Difference? Medical Journal of Australia, 167, $236-237$.

[7] Davis, D.A., Thomson, M.A., Oxman, A.D. and Haynes, R.B. (1995) Changing Physician Performance: A Systematic Review of the Effect of Continuing Medical Education Strategies. JAMA, 274, 700-705. http://dx.doi.org/10.1001/jama.1995.03530090032018

[8] Moellem, M. (2001) Applying Constructivist and Objectivist Learning Theories in the Design of a Web-Based Course: Implications for Practice. Educational Technology \& Society, 4, 113-125.

[9] Lee, J. and Jang, S. (2014) A Methodological Framework for Instructional Design Model Development: Critical Dimensions and Synthesized Procedures. Educational Technology Research and Development, 62, 743-765. http://dx.doi.org/10.1007/s11423-014-9352-7

[10] Morrison, G.R. (2010) Designing Effective Instruction. 6th Edition, John Wiley \& Sons, Hoboken, New Jersey.

[11] Department of Health (2015) Allied Health Professions Project: Demonstrating Competence through Continuing Professional Development [CPD]. http://webarchive.nationalarchives.gov.uk/+/www.dh.gov.uk/en/consultations/closedconsultations/DH_4071458

[12] Battles, J.B. (2006) Proving Patient Safety by Instructional Systems Design. Quality \& Safety in Health Care, 15, 2529. http://dx.doi.org/10.1136/qshc.2005.015917

[13] COT-for-MRCGP-Workplace-Based-Assessment (2015).

http://www.rcgp.org.uk/training-exams/mrcgp-workplace-based-assessment-wpba/cot-for-mrcgp-workplace-based-ass essment.aspx 


\section{Appendix 1: Needs Assessment}

\section{Dear colleague:}

As an endeavor to promote doctors' performance in the division, we seek your collaboration as a member to actively participate in the doctors' on-the-job training program. In order to tailor the program to the needs and demands of the doctors, we ask you to complete this form. The results will help us to build up a program that responds to your needs and helps enhance your competencies and performance.

Name: (optional)

Doctor's title: Registrar $\square$ Resident

Have you had formal training in family medicine: Yes $\square$ No

How many years of training have you had in family medicine? Years:

How many years of experience in family medicine do you have? Years:

Do you have any special area of interest? Yes $\square$ No $\square$

Please specify

Have you had any training in the doctor-patient interaction/ commutation skills? Yes $\square$ No $\square$

Regarding the previous question, what type of training have you had?

Formal $\square$ Non-formal $\square$ Other (please explain)

Plan of activities:

What is your preferred frequency for this program? Daily

What is/are your preferred form/s of learning?

Twice a week $\square$ Weekly

$\begin{array}{lll}\text { Lecture } & \square & \text { Group discussion } \\ \text { One-to-one } & \square & \text { Clinical observation } \\ \text { Case-based discussion } & \square & \text { Peer review }\end{array}$

Other (please specify)

Would you prefer practical sessions? Yes $\square$ No

Would you like to have sessions on special procedures and hands-on skills? Yes $\square$ No

Others (please specify)

In what areas of your daily work do you feel that you need improvement?

\begin{tabular}{ll}
\hline & Main area \\
\hline • & Adult medicine \\
- & Pediatrics \\
- & Geriatric \\
- & Women's health \\
- & Psychiatry \\
- & Derma \\
- & Eye \\
- & ENT \\
- & Prevention \\
- & Lab \\
- & Imaging \\
\hline
\end{tabular}




\section{In what areas would you like to contribute during this program?}

\begin{tabular}{lllll}
\hline$\bullet$ & Organization & $\square$ & $\bullet$ & IT skills \\
$\bullet$ & Topic preparation & $\square$ & Research & $\square$ \\
$\bullet$ & Group facilitation & $\square$ & & \\
\hline
\end{tabular}

\section{Thank you}

\section{Appendix 2}

Consultation observation sheet ${ }^{1}$.

\begin{tabular}{|c|c|c|c|c|c|}
\hline & \multirow[b]{2}{*}{ Observed competencies } & \multicolumn{4}{|c|}{ Grading } \\
\hline & & Insufficient & $\begin{array}{c}\text { Needs } \\
\text { Improvement }\end{array}$ & Sufficient & Excellent \\
\hline A & Discovers the reason for the patient attendance & & & & \\
\hline 1 & Encourages the patient's contribution & & & & \\
\hline 2 & Responds to cues & & & & \\
\hline 3 & Places complaints in appropriate psychological context & & & & \\
\hline 4 & Explores patient's health understanding & & & & \\
\hline B & Defines the clinical problem & & & & \\
\hline 5 & Includes or excludes likely relevant significant condition & & & & \\
\hline 6 & Conducts appropriate physical or mental state examination & & & & \\
\hline 7 & Makes an appropriate working diagnosis & & & & \\
\hline C & Explains the problem in appropriate language & & & & \\
\hline 8 & Explains the problem in appropriate language & & & & \\
\hline $\mathbf{D}$ & Addresses the patient's problem & & & & \\
\hline 9 & Seeks to confirm the patient's understanding & & & & \\
\hline 10 & Provides an appropriate management plan & & & & \\
\hline 11 & Involves patient in management decisions & & & & \\
\hline $\mathbf{E}$ & Makes effective use of the consultation & & & & \\
\hline 12 & Makes effective use of resources & & & & \\
\hline 13 & Specifies conditions and interval for follow up & & & & \\
\hline
\end{tabular}

\section{Overall assessment}

Feedback and recommendations for further development

\footnotetext{
${ }^{1}$ Adapted from the COT Consultation Observation Tool (Royal College of General Practitioners n.d.) [13].
} 


\section{Submit or recommend next manuscript to SCIRP and we will provide best service for you:}

Accepting pre-submission inquiries through Email, Facebook, LinkedIn, Twitter, etc.

A wide selection of journals (inclusive of 9 subjects, more than 200 journals)

Providing 24-hour high-quality service

User-friendly online submission system

Fair and swift peer-review system

Efficient typesetting and proofreading procedure

Display of the result of downloads and visits, as well as the number of cited articles

Maximum dissemination of your research work

Submit your manuscript at: http://papersubmission.scirp.org/ 